\title{
Studi Kuat Tekan Beton Porus sebagai Material Alternatif Batu Bata dengan Metode Taguchi
}

\author{
Ridho Bayuaji \\ Prodi Diploma Jurusan Teknik Sipil FTSP ITS J1 Menur 127 Surabaya \\ Email:bayuaji@ce.its.ac.id
}

\begin{abstract}
Foamed concrete is a porous lightweight concrete. It is produced by mixing portland cement paste or mortar and stable foam, with no coarse aggregate. Indeed, foamed concrete was initially functionalized as filling materials, insulation materials, and highway reinstatement use. Foamed concrete can be designed to have any density from as low as $400 \mathrm{~kg} / \mathrm{m}^{3}$ to $1600 \mathrm{~kg} / \mathrm{m}^{3}$, thus contributing to reduce dead load. The density of the material depends on the number and size of the stable foam. The steady foams are formed by suitable foaming agent produces homogenous void structure in foamed concrete mixes. The air-voids are too far apart to have an influence on the compressive strength. Therefore it is necessary to explore the strength of foamed concrete to fulfill the strength of bricks. The Taguchi approach was used to arrange experimental design with 4 variables and 3 levels. 150 by $300 \mathrm{~mm}$ cylinders were prepared for 28 day compressive strength. The calculations for compressive strength were conducted in accordance with SNI-03-1974-1990. This study clearly indicates that the foamed concrete strength was more than $100 \mathrm{~kg} / \mathrm{cm}^{2}$, the lowest requirement (NI-10, 1978), for brick strength
\end{abstract}

Keywords: Foamed concrete, Density, Compressive Strength, Lighweight Concrete, Brick.

Abstrak

Beton porus adalah beton ringan yang dibuat dari pasta semen atau mortar dan busa udara, tanpa ada unsur agregat kasar (AK). Penelitian terdahulu menunjukkan bahwa beton porus mempunyai fungsi material pengisi, bahan isolasi dan pemuliha ketinggian jalan raya. Salah satu kelebihan beton porus adalah variasi berat volume antara $400-1600 \mathrm{~kg} / \mathrm{m}^{3}$ sehingga mengurangi beban mati. Busa udara yang dimasukkan dalam pasta semen atau mortar menghasilkan variasi densitas beton porus. Rongga atau pori dalam mortar perlu dilakukan studi untuk menjelaskan kuat tekan beton porus agar memenuhi persyaratan batu bata. Penelitian ini bertujuan untuk mengembangkan teknologi beton ringan, beton porus agar dapat diaplikasikan sebagai material alternatif pengganti batu bata. Desain eksperimen yang digunakan untuk mengoptimalisasi bahan penyusun BRF adalah menggunakan metode Taguchi, dengan 4 variabel dan 3 level. Benda uji beton ringan yang digunakan adalah silinder dengan diameter $150 \mathrm{~mm}$ dan tinggi $300 \mathrm{~mm}$, dilakukan uji tekan dengan standar SNI-03-19741990 pada umur hidrasi 28 hari. Penelitian ini memberi kesimpulan beton porus mempunyai kuat tekan yang memenuhi mutu I kuat tekan tekan standar bata merah sebagai material alternatif pengganti batu bata.

Kata kunci: Beton Porus, Densitas, Kuat Tekan, Beton Ringan, Bata.

\section{Pendahuluan}

Kebutuhan tempat tinggal akan mengikuti laju pertumbuhan penduduk. Laju pertumbuhan penduduk di Indonesia diperkirakan sebesar $1,49 \%$ per tahun akan memberikan prediksi jumlah penduduk di Indonesia pada tahun 2014 akan mencapai 259 juta jiwa (BPS,
2013), hal ini secara tak langsung berimbas pada peningkatan kebutuhan tempat tinggal.

Saat ini peningkatan kebutuhan rumah diwujudkan dengan pembangunan berbagai kelas rumah mulai dari sederhana (non-engineered) sampai dengan rumah mewah.

Jurnal APLIKASI: Media Informasi \& Komunikasi Aplikasi Teknik Sipil Terkini Halaman 57 
Ramainya kegiatan pembangunan perumahan berakibat memunculkan inovasiinovasi penelitian material bahan bangunan, khususnya untuk material dinding, yang bertujuan memenuhi kebutuhan material yang murah, terjangkau, praktis dan aman bagi pemakai.

Batu bata adalah bahan bangunan yang paling banyak dipakai sebagai material dinding rumah. Di Indonesia, jenis batu bata yang umum digunakan adalah batu bata yang terbuat dari bahan dasar tanah liat atau lempung. Bahan dasar tersebut terdapat di lahan-lahan pertanian yang subur. Jika tidak dilakukan perubahan mindset kepada masyarakat yang masih menggunakan industri batu bata dari tanah liat akan berakibat ancaman terhadap lokasi lahan pertanian (Suntoro, 2006). Apabila kegiatan tersebut tidak dikelola dengan baik, maka akan mengakibatkan terjadinya degradasi lahan pertanian yang mengancam keberlanjutan usaha tani dan ketahanan pangan (Suntoro, 2006). Oleh karenanya, dalam kegiatan pembangunan hendaknya harus dipikirkan keberlanjutannya dimasa mendatang (sustainabilitas). Pembangunan yang berkelanjutan banyak memberikan peluang bagi banyak orang. Apalagi ditunjang pendapatan yang semakin meningkat sehingga memberikan kesempatan untuk memenuhi kebutuhan utama, seperti perumahan.

Inovasi bahan bangunan saat ini dan masa depan adalah: ringan, kuat, tahan lama, mudah digunakan, ekonomis dan lebih ramah lingkungan (Bayuaji, 2011). Pemahaman karakteristik suatu material penyusun batu bata dengan teliti, akan memberikan manfaat yang maksimal (Bayuaji, 2010).

Oleh sebab itu penelitian ini memberikan peluang dalam kreasi material utama pendukung dalam pembangunan rumah tinggal menggunakan beton ringan, beton porus.

Beton porus dengan sistem foam agent mempunyai banyak kelebihan. Kelebihan pertama densitas yang bisa dimodifikasi sehingga dapat mengurangi beban mati. Selain ringan, material penyusun beton porus dapat memanfaatkan material limbah seperti fly ash, abu gunung berapi (Bayuaji, 2011), abu lumpur (Nuruddin, 2010), abu sekam padi (Bayuaji, 2014a, Bayuaji, 2014b) dan bahan pozzolan dari limbah rumah tangga dan industri lainnya.

Kolaborasi pemanfaatan bahan limbah dan pengembangan teknologi beton porus mempunyai prospek pemanfaatannya yang luas sebagai material alternatif bahan bangunan ke depan.

\subsection{Bata Merah}

Bata merah adalah produk teknologi sederhana dan mempunyai manfaat langsung kepada masyarakat dalam kelengkapan kebutuhan rumah tinggal. Definisi bata merah, bata yang dibuat dari tanah liat dengan atau tanpa campuran bahan lainnya yang dibakar pada suhu yang cukup tinggi hingga tidak hancur lagi bila direndam dalam air (SII-0021-78, 1978) dan mempunyai luas penampang yang berlubang kurang dari $15 \%$ dari luas potongan datarnya (SKSNI-S-04-1989-F, 1989).

Halaman 58 Jurnal APLIKASI: Media Informasi \& Komunikasi Aplikasi Teknik Sipil Terkini 
Walau teknologi sederhana namun Indonesia mempunyai standar untuk kualitas dan kuantitas batu bata merah yang dijelaskan pada Tabel 1, Tabel 2 dan Tabel 3. Pada tabel tersebut diterangkan ukuran bata merah standar (SNI-2094-2000), kuat tekan sesuai standar (NI-10, 1978) dan variasi kuat tekan. (SII-0021-78, 1978)

Tabel 1. Dimensi standar ukuran bata merah

\begin{tabular}{lccc}
\hline Ukuran & $\begin{array}{c}\text { Ukuran 1 } \\
(\mathrm{mm})\end{array}$ & $\begin{array}{c}\text { Ukuran 2 } \\
(\mathrm{mm})\end{array}$ & $\begin{array}{c}\text { Penyimpa- } \\
\text { ngan } \\
\text { maksimum }\end{array}$ \\
\hline Panjang & 240 & 230 & 3 \\
Lebar & 115 & 110 & 4 \\
Tebal & 52 & 50 & 5 \\
\hline
\end{tabular}

Tabel 2. Kuat tekan standar bata merah

\begin{tabular}{lll}
\hline Mutu & $\begin{array}{l}\text { Kuat tekan rata-rata } \\
\left(\mathrm{Kg} / \mathrm{cm}^{2}\right)\end{array}$ & $\begin{array}{l}\text { Penyimpangan } \\
\text { maksimum }\end{array}$ \\
\hline I & $>100$ & $\begin{array}{l}\text { Tidak ada } \\
\text { penyimpangan }\end{array}$ \\
& & 1 dari 10 \\
II & $80-100$ & $2-10$ \\
III & $60-80$ & \\
\hline
\end{tabular}

Tabel 3. Kuat tekan dan variasi bata merah yang diijinkan

\begin{tabular}{cccc}
\hline Kelas & $\begin{array}{c}\text { Kuat tekan rata-rata } \\
\text { minimum dari 30 buah } \\
\text { bata yang diuji }\end{array}$ & $\begin{array}{c}\text { Koefisien } \\
\text { variasi yang } \\
\text { diijinkan } \\
\text { dari rata- } \\
\text { rata kuat } \\
\text { tekan bata } \\
\text { yang diuji }\end{array}$ \\
\cline { 2 - 4 } & & & $\%$ \\
\hline 25 & 25 & 2.5 & 22 \\
50 & 50 & 5 & 22 \\
100 & 100 & 10 & 22 \\
150 & 150 & 15 & 15 \\
200 & 200 & 20 & 15 \\
250 & 250 & 25 & 15 \\
\hline
\end{tabular}

\subsection{Beton ringan dengan sistem Foam Agent (BRF)}

Istilah beton porus adalah beton ringan dengan konsep mencampurkan busa udara stabil yang dibuat dari foam agent dan air (Bayuaji, 2010) ke dalam semen pasta atau mortar (Ramamurthy et al., 2009), akibatnya mortar tersebut mempunyai pori yang cukup banyak dan merata sehingga beton ini menjadi ringan. Jenis beton ini oleh American Society for Testing and Material (ASTM) disebut dengan Celluler Lightweight Concrete (CLC), dalam makalah ini diberi istilah Beton Ringan sistem Foam agent (BRF).

Saat ini BRF telah banyak diproduksi dan diteliti oleh banyak negara seperti Jerman (A. Just and Middendorf, 2009), Inggris (Jones and McCarthy, 2005), Afrika Selatan (Kearsley and Mostert, 2005), bahkan India (Ramamurthy et al., 2009) sebagai material non struktural seperti dinding, thermal insulation dan lain sebagainya.

Berat jenis BRF berkisar antara 300 hingga $1800 \mathrm{~kg} / \mathrm{m}^{3}$ dan kekuatan tekan antara 0,3 hingga $25 \mathrm{Mpa}$ (ACIcommittee523., 1975).

Beberapa keuntungan pemanfaatan BRF (Bayuaji, 2011), yaitu: (i) BRF memberikan kontribusi dalam bidang teknologi beton, khususnya beton ringan dengan bervariasi berat volumenya antara 300 to $1800 \mathrm{~kg} / \mathrm{m}^{3}$. Hal ini memberikan keleluasaan perencanaan beban sendiri dan memungkinkan untuk didesain lebih kecil. Sehingga berat sendiri tersebut dapat mengurangi perhitungan suatu elemen struktur, contoh:,

Jurnal APLIKASI: Media Informasi \& Komunikasi Aplikasi Teknik Sipil Terkini Halaman 59 
pelat lantai, pelat pengisi dinding partisi, insulasi dan leveling; (ii) Berkontribusi dalam proses pelaksanaan pengecoran, BRF segar mempunyai kelecakan yang baik sehingga mudah mengalir, proses pemadatan memanfaatkan gravitasi dan padat dengan sendirinya; (iii) Mampu mengisi antar tulangan tanpa menggunakan peralatan pemadat beton segar sehingga mengurangi kebisingan selama pelaksanaan; (iv) Bahan material yang terbuat dari BRF akan mengurangi beban transportasi dan jumlah operator selama proses mobilisasi; (v) Menyerap panas yang baik dan material tahan api karena jumlah rongga di beton; (vi) Peredam benturan dan beban kejut yang baik.

\section{Metodologi}

Untuk mencapai tujuan penelitian ini, maka dilakukan eksperimen di laboratorium Prodi DIII Teknik Sipil FTSP ITS. Adapun material yang digunakan dalam penelitian ini mempunyai kriteria sebagai berikut:

Semen Gresik tipe I digunakan sebagai material pengikat campuran. Sifat fisik dan kimia semen diuraikan pada Tabel 4. Densiti dan luas partikel semen diketahui masing-masing 3,15 dan 359 $\mathrm{m}^{2} / \mathrm{kg}$. Agregat halus yang digunakan dalam eksperimen ini adalah pasir alami quartzite yang diperoleh dari depo Mojokerto. Modulus halus butir sebesar 3,119 , diameter butiran dari $0,15 \mathrm{~mm}$ hingga $0,85 \mathrm{~mm}$, kelembaban 1,46\%, berat jenis $2,73 \mathrm{gr} / \mathrm{cm}^{3}$, resapan sebesar $0,77 \%$, buckling $15,38 \%$, kandungan organik rendah, kandungan lumpur 3\%.
Table 4. Properti semen sebagai bahan pengikat

\begin{tabular}{|c|c|c|}
\hline Parameter & $\begin{array}{c}\text { SNI 15- } \\
2049- \\
2004\end{array}$ & $\begin{array}{c}\text { Hasil } \\
\text { Tes }\end{array}$ \\
\hline \multicolumn{3}{|l|}{ Komposisi Kimia } \\
\hline $\mathrm{Al}_{2} \mathrm{O}_{3}$ & & 6.03 \\
\hline $\mathrm{SiO}_{2}$ & & 20.65 \\
\hline $\mathrm{Fe}_{2} \mathrm{O}_{3}$ & & 3.44 \\
\hline \multirow[t]{2}{*}{$\mathrm{CaO}$} & & 65.96 \\
\hline & Max & \\
\hline $\mathrm{MgO}$ & $\begin{array}{l}6.00 \\
\text { Max }\end{array}$ & 2.05 \\
\hline $\mathrm{SO}_{3}$ & $\begin{array}{l}3.50 \\
\operatorname{Max}\end{array}$ & 2.22 \\
\hline Loss on Ignition & 5.00 & 3.96 \\
\hline Free Lime & & 1.09 \\
\hline $\begin{array}{l}\text { Insoluble residue } \\
\text { Alkali }\end{array}$ & & 2.37 \\
\hline$\left(\mathrm{Na}_{2} \mathrm{O}+0,658 \mathrm{~K}_{2} 0\right)$ & & 0.38 \\
\hline \multicolumn{3}{|l|}{ Propoerti X-Ray } \\
\hline \multicolumn{3}{|l|}{ Tricalcium Silicate } \\
\hline \multicolumn{3}{|l|}{ Dicalcium Silicate } \\
\hline \multicolumn{3}{|l|}{ Tricalcium Aluminate } \\
\hline $\begin{array}{c}\text { Tetracalcium } \\
\text { Aluminate Ferrite } \\
\text { (C4AF) }\end{array}$ & & 8.91 \\
\hline \multicolumn{2}{|l|}{ Properti Fisik } & \\
\hline $\begin{array}{l}\text {-Blaine specific } \\
\text { surface }\left(\mathrm{m}^{2} / \mathrm{kg}\right)\end{array}$ & Min 280 & 359 \\
\hline \multicolumn{3}{|l|}{ Waktu setting, Vicat } \\
\hline - Initial set (minutes) & Min 45 & 125 \\
\hline - final set (menit) & Max 375 & 240 \\
\hline $\begin{array}{l}\text { Autoclave test: } \\
\text {-Expansion (\%) } \\
\text { Kuat Tekan: }\end{array}$ & Max 0.8 & 0.10 \\
\hline - 3 hari $\left(\mathrm{kg} / \mathrm{cm}^{2}\right)$ & Min 125 & 255 \\
\hline-7 hari $\left(\mathrm{kg} / \mathrm{cm}^{2}\right)$ & Min 200 & 316 \\
\hline - 28 hari $\left(\mathrm{kg} / \mathrm{cm}^{2}\right)$ & Min 280 & 411 \\
\hline False set $(\%)$ & Min 50 & 77,36 \\
\hline
\end{tabular}


Penelitian ini didesain untuk menyertakan semua parameter yang dinilai memberi pengaruh signifikan terhadap kekuatan BRF, juga didesain untuk meminimalkan percobaan dan yang paling penting mudah dalam menganalisa hasil eksperimen yang telah dilaksanakan. Metode yang dipilih dalam mendesain eksperimen ini adalah metode Taguchi dengan orthogonal array (Tabel 5), L9 $\left(3^{4}\right)$ dengan menjalankan sekaligus 4 parameter (Pasir/semen, diameter pasir, air/zat padatan, densiti) yang dianggap memberi pengaruh kuat terhadap kekuatan.

Tabel 5. Orthogonal array (Roy, 1990.) yang diaplikasikan untuk penelitian ini

\begin{tabular}{lcccc}
\hline Jumlah Eksperimen & \multicolumn{4}{c}{ Variabel } \\
\cline { 2 - 5 } & A & B & C & D \\
\hline BRF-1 & 1 & 1 & 1 & 1 \\
BRF-2 & 1 & 2 & 2 & 2 \\
BRF-3 & 1 & 3 & 3 & 3 \\
BRF-4 & 2 & 1 & 2 & 3 \\
BRF-5 & 2 & 2 & 3 & 1 \\
BRF-6 & 2 & 3 & 1 & 2 \\
BRF-7 & 3 & 1 & 3 & 2 \\
BRF-8 & 3 & 2 & 1 & 3 \\
BRF-9 & 3 & 3 & 2 & 1 \\
\hline
\end{tabular}

Ditetapkan variabel dan tingkatan level sebagai berikut:
A : Variabel Pasir/Semen $=0,25$; 0,$5 ; 0,75$ untuk level $1 ; 2 ; 3$
B : Variabel diameter pasir $=$ (a) 0,15-.0,4 mm; (b) 0,3-.0,6 mm; (c) $0,4-.0,85 \mathrm{~mm}$ untuk level 1 ; $2 ; 3$
C : Variabel Air/zat padatan $=0,3$; 0,$35 ; 0,4$ untuk level 1, 2, 3
D : Variabel Densiti $=1000 ; 1250$ ; 1500 untuk level 1, 2, 3

Tingkatan level ini disusun sesuai orthogonal array yang direncakan maka dipresentasikan desain komposisi seperti pada Tabel 6 dan Tabel 7 sebagai berikut:

Tabel 6. Desain komposisi dan level BRF

\begin{tabular}{ccccc}
\hline & & \multicolumn{3}{c}{ Air/za } \\
Mix & $\begin{array}{c}\text { Pasir/ } \\
\text { Semen }\end{array}$ & $\begin{array}{c}\text { Dia. Pasir } \\
(\mathrm{mm})\end{array}$ & $\begin{array}{c}\mathrm{t} \\
\text { padata } \\
\mathrm{n}\end{array}$ & $\begin{array}{c}\text { Densi } \\
\mathrm{ti}\end{array}$ \\
\hline BRF-1 & 0.25 & $0,15-.0,4$ & 0,3 & 1000 \\
BRF-2 & 0.25 & $0,3-.0,6$ & 0,35 & 1250 \\
BRF-3 & 0.25 & $0,4-.0,85$ & 0,4 & 1500 \\
BRF-4 & 0.5 & $0,15-.0,4$ & 0,35 & 1500 \\
BRF-5 & 0.5 & $0,3-.0,6$ & 0,4 & 1000 \\
BRF-6 & 0.5 & $0,4-.0,85$ & 0,3 & 1250 \\
BRF-7 & 0.75 & $0,15-.0,4$ & 0,4 & 1250 \\
BRF-8 & 0.75 & $0,3-.0,6$ & 0,3 & 1500 \\
BRF-9 & 0.75 & $0,4-.0,85$ & 0,35 & 1000 \\
\hline
\end{tabular}

Tabel 7. Keperluan bahan penyusun BRFAVB

\begin{tabular}{ccccccc}
\hline \multirow{2}{*}{ Mix } & Semen & Air & Foam & \multicolumn{3}{c}{ Dia. Pasir (mm) } \\
\cline { 5 - 7 } & $(\mathrm{Kg})$ & $(\mathrm{Kg})$ & $(\mathrm{Ltr})$ & $(\mathrm{a})$ & $(\mathrm{b})$ & $(\mathrm{c})$ \\
\hline BRF-1 & 48.9 & 18.4 & 41.0 & 12 & & \\
BRF-2 & 58.9 & 25.8 & 29.5 & & 15 & \\
BRF-3 & 68.2 & 34.1 & 17.4 & & & 17 \\
BRF-4 & 58.9 & 30.9 & 18.8 & 30 & & \\
BRF-5 & 37.9 & 22.7 & 37.6 & & 19 & \\
BRF-6 & 51.0 & 22.9 & 30.8 & & & 26 \\
BRF-7 & 40.6 & 28.4 & 26.8 & 30 & & \\
BRF-8 & 52.4 & 27.5 & 20.5 & & 40 & \\
BRF-9 & 33.7 & 20.6 & 38.7 & & & 25 \\
\hline
\end{tabular}

Proses selanjutnya adalah pembuatan benda uji BRF yang dicetak pada silinder diameter $150 \mathrm{~mm}$ dan tinggi $300 \mathrm{~mm}$, masing-masing mix ada 6 benda uji. Komposisi disesuaikan dengan desain eksperimen metode Taguchi. Benda uji BRF dilakukan uji tekan dengan standar SNI-03-19741990 pada umur 28 hari untuk kuat tekan. Benda uji BRF dibuka dari cetakan dengan waktu minimal 24 jam dari awal waktu mencetak. Pe-

Jurnal APLIKASI: Media Informasi \& Komunikasi Aplikasi Teknik Sipil Terkini Halaman 61 
nyimpanan dan perawatan benda uji BRF dilakukan dengan cara direndam dalam air. Untuk mengetahui seberapa besar beban yang mampu ditahan oleh BRF, maka dilakukan pengujian kuat tekan BRF arah vertikal hingga mencapai gaya tekan yang menyebabkan benda uji hancur.

\section{Hasil dan Pembahasan}

Untuk menjawab tujuan penelitian ini, hasil eksperimen yang telah didesain dengan metode Taguchi, berikutnya digambar korelasi pengaruh variabel dengan target kuat tekan BRF. Korelasi ini diterangkan pada Gambar 1. Variabel rasio semen dan pasir mempunyai pola korelasi yang sama dengan diameter pasir, semakin besar nilai varibel mengakibatkan nilai kuat tekan menurun. Hasil kuat tekan rata-rata BRF-1 s.d BRF-9 ditampilkan pada Tabel 8 . Pada umur hidrasi 28 hari data BRF menunjukkan nilai antara antara 140 $\mathrm{kg} / \mathrm{cm}^{2}$ s.d $221 \mathrm{~kg} / \mathrm{cm}^{2}$. Masing-masing variabel dianalisa dengan ANOVA (analysis of variance) yang akan ditunjukkan secara rinci pada Tabel 9. Dari tabel ini akan diketahui kontribusi masing-masing variabel dalam menyusun targetnya yaitu kuat tekan BRF yang maksimum. Kontribusi variabel terbesar yang berpengaruh terhadap kuat tekan beton porus dipengaruhi Densitas dan Pasir/Semen dengan kontribusi sebesar $41,5 \%$ dan $34,3 \%$ secara beurutan.
Tabel 8. Kuat tekan rata-rata BRF dalam satuan $\mathrm{kg} / \mathrm{cm}^{2}$

\begin{tabular}{cc}
\hline Mix & Kuat tekan $\left(\mathrm{kg} / \mathrm{cm}^{2}\right)$ \\
\hline BRF-1 & 191 \\
BRF-2 & 204 \\
BRF-3 & 206 \\
BRF-4 & 221 \\
BRF-5 & 145 \\
BRF-6 & 140 \\
BRF-7 & 154 \\
BRF-8 & 181 \\
BRF-9 & 149 \\
\hline
\end{tabular}

Tabel 9. Hasil ANOVA dari kuat tekan BRF

\begin{tabular}{|c|c|c|}
\hline Variabel & $\begin{array}{c}\text { Parameter } \\
\text { statistik }\end{array}$ & $\begin{array}{c}\text { Kuat tekan } \\
\text { umur } 28 \text { hari }\end{array}$ \\
\hline \multirow{6}{*}{ Pasir/Semen } & $\overline{\mathrm{DF}^{\mathrm{a}}}$ & 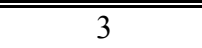 \\
\hline & $\mathrm{SSS}^{\mathrm{b}}$ & 15167 \\
\hline & $\mathrm{ASS}^{\mathrm{c}}$ & 15167 \\
\hline & $\mathrm{MS}^{\mathrm{d}}$ & 5056 \\
\hline & F test & 19.77 \\
\hline & Kontribusi & $34.3 \%$ \\
\hline \multirow{7}{*}{$\begin{array}{c}\text { Diameter } \\
\text { Pasir }\end{array}$} & DF & 3 \\
\hline & SSS & 4986 \\
\hline & ASS & 4986 \\
\hline & MS & 1662 \\
\hline & F test & 6.50 \\
\hline & Kontribusi & $11.3 \%$ \\
\hline & DF & 3 \\
\hline \multirow{4}{*}{$\begin{array}{l}\text { Air/zat } \\
\text { padat }\end{array}$} & SSS & 5731 \\
\hline & ASS & 5731 \\
\hline & MS & 1910 \\
\hline & F test & 7.47 \\
\hline \multirow{7}{*}{ Densiti } & Kontribusi & $13.0 \%$ \\
\hline & DF & 3 \\
\hline & SSS & 18337 \\
\hline & ASS & 18337 \\
\hline & MS & 6112 \\
\hline & F test & 23.90 \\
\hline & Kontribusi & $41.5 \%$ \\
\hline \multicolumn{3}{|c|}{ a : derajad kebebasan } \\
\hline \multicolumn{3}{|c|}{ b: jumlah kuadrat } \\
\hline \multicolumn{3}{|c|}{$\mathrm{c}:$ jumlah kuadrat (derajad kebebasan) } \\
\hline
\end{tabular}

Halaman 62 Jurnal APLIKASI: Media Informasi \& Komunikasi Aplikasi Teknik Sipil Terkini 


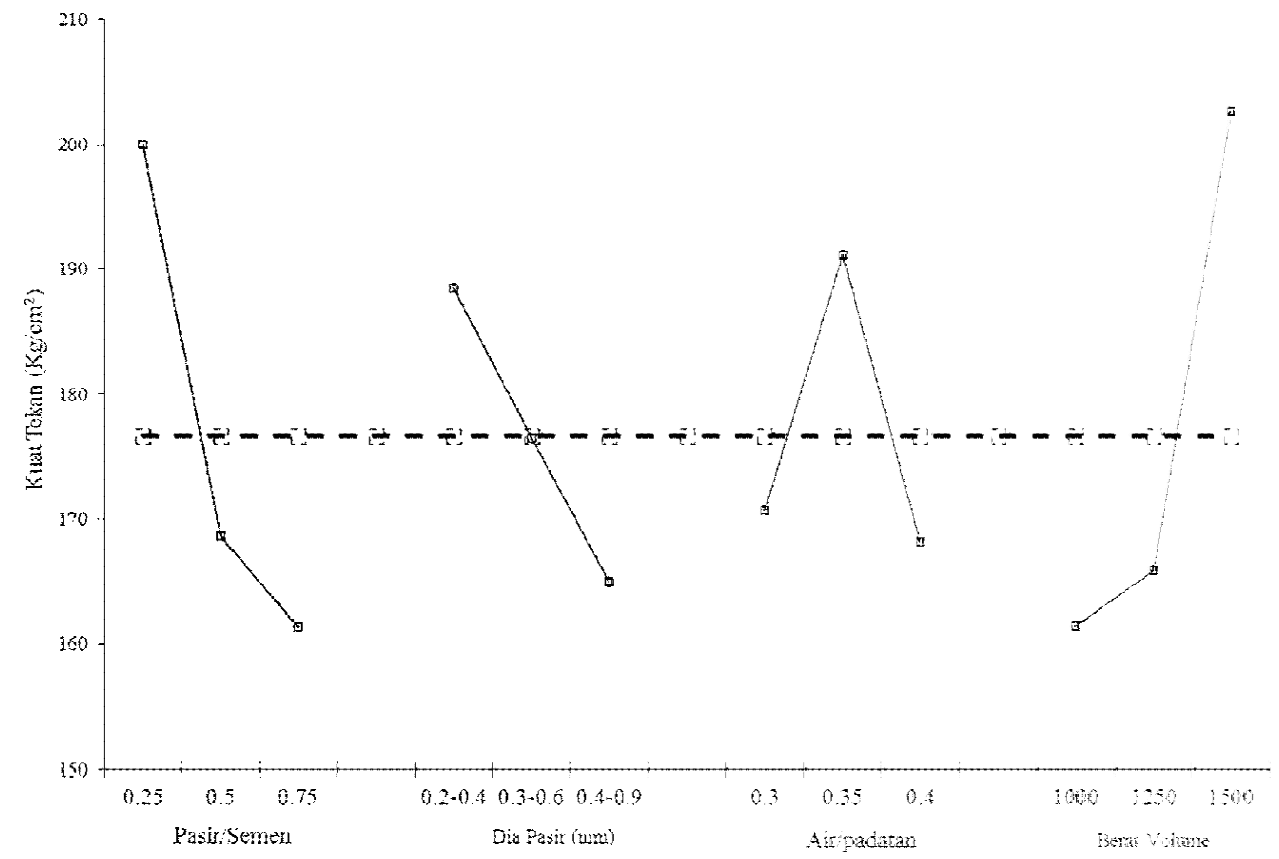

Gambar 1. Pengaruh 4 variabel utama pada kuat tekan BRF umur 28 hari

\section{Simpulan}

Penelitian ini memberi simpulan terhadap desain eksperimen, variabel dan kekuatan yang dicapai. Pertama, metode desain eksperimen Taguchi L9 $\left(3^{4}\right)$ telah berhasil memberikan komposisi penyusun BRF untuk mencapai kuat tekan BRF yang maksimal yaitu dengan komposisi: pasir/semen, diameter pasir, air/zat padatan dan densiti yaitu: $0,25,0,15-0.4,0,35$ dan 1500 $\mathrm{kg} / \mathrm{cm}^{2}$. Kedua, variabel yang dominan mempengaruhi kuat tekan beton porus adalah densitas yang diinginkan dan rasio pasir dengan semen. Ketiga, tujuan penelitian ini memberi simpulan beton porus mempunyai kuat tekan yang memenuhi mutu I kuat tekan tekan standar bata merah sebagai material alternatif pengganti batu bata yatitu dengan kuat tekan rata-rata BRF 177 $\mathrm{kg} / \mathrm{cm}^{2}$, lebih tinggi $77 \%$ standar bata merah pejal.

\section{Daftar Pustaka}

A. Just, and Middendorf, B., 2009. Microstructure of high-strength foam concrete. Materials Characterization 60, 741-748.

ACI-committee523. 1975. Guide for cellular concretes above $50 \mathrm{pcf}$, and for aggregate concretes above 50 pcf with compressive strengths less than 2500 psi. . ACI Journal 72, 50-66.

Bayuaji, R., 2010. Effects Of Microwave Incinerated Rice Husk Ash (Mirha) On Hydration And Mechanical Properties Of Foamed Concrete. Dissertation, Universiti Teknologi Petronas, Bandar Sri Iskandar, Malaysia.

Jurnal APLIKASI: Media Informasi \& Komunikasi Aplikasi Teknik Sipil Terkini Halaman 63 
Bayuaji, R., 2011a. Studi Literatur dan Prospek Penelitian Beton Porus Sebagai Material Struktur dan Bahan Bangunan In "Seminar Nasional Aplikasi Teknologi Prasarana Wilayah 2011", Prodi Diploma Teknik Sipil FTSP ITS.

Bayuaji, R., 2011b. Characterization of Pozzolanicity Bromo's Volcanic Ash In Proceedings of International Seminar on Applied Technology, Science, and Arts (3rd APTECS), Surabaya, 6 Dec. 2011, ISSN 2086-1931", Surabaya, Indonesia, ITS.

Bayuaji, R., 2014a. The Influence of Burning Temperature of MIRHA On Mechanical Properties of Foamed Concrete, IPTEK, Journal of Proceeding Series, Vol. 1, 2014 (eISSN: 2354-6026)

Bayuaji, R., 2014b. Influence of Microwave Incinerated Rice Husk Ash on Hydration of Foamed Concrete, Advances in Civil Engineering Volume 2014, Article ID 482176, 8 pages http://dx.doi.org/10.1155/2014/4 82176

BPS., 2013. Sosial dan Kependudukan.

Jones, M. R., and McCarthy, A., 2005. Behaviour and assessment of foamed concrete for construction applications. In "Proceedings of the International Conference on the Use of Foamed Concrete in Construction", pp. 61-88.
Kearsley, E. P., and Mostert, H. F., 2005. The use of foamed concrete in refractories. In "Proceedings of the International Conference on the Use of Foamed Concrete in Construction", pp. 89-96.

NI-10. 1978. "Bata Merah Sebagai Bahan Bangunan."

Nuruddin, M.F.; Bayuaji, R.; Masilamani, M.B.; Biyanto. 2010. T.R. Sidoarjo mud: A potential cement replacement material. Civ. Eng. Dimension 2010, 12, 18-22.

Ramamurthy, K., Nambiar, E. K. K., and Ranjani, G. I. S., 2009. A Classification of Studies on Properties of Foam Concrete. Cement \& Concrete Composites S0958-9465(09)00063-8.

Roy, R., 1990. A primer on the Taguchi method.

SII-0021-78, 1978. "Mutu dan Uji Bata Merah Pejal," Yayasan LPMB, Bandung.

SKSNI-S-04-1989-F., 1989. "Spesifikasi Bahan Bangunan," Bandung.

SNI-2094-2000 Bata Merah Pejal untuk Pasangan Dinding."

Suntoro, W., 2006. Degradasi Lahan dan Ancaman bagi Pertanian In "Solo Pos", Solo.

Halaman 64 Jurnal APLIKASI: Media Informasi \& Komunikasi Aplikasi Teknik Sipil Terkini 